\title{
INVESTIGATIONS ON THE PROCESS OF LEAD REMOVAL FROM CU-Pb ALLOYS DURING THEIR MELTING IN VACUUM INDUCTION FURNACE
}

\begin{abstract}
The paper presents analysis and assessment of operating power of vacuum induction furnace in relation to the efficiency of lead removal from $\mathrm{Cu}-\mathrm{Pb}$ alloy in VIM (vacuum induction melting) technology. Thermodynamic analysis of the process is performed as well.

Keywords: VIM technology, evaporation, $\mathrm{Cu}-\mathrm{Pb}$ alloys
\end{abstract}

\section{Introduction}

Vacuum induction furnaces belong to a group of modern metallurgical aggregates which are used in the smelting process of metals and alloys of high purity. Metal melting carried out in such devices causes not only their degassing but also removal of metallic bath impurities through their evaporation [1-6]. Evaporation process is a heterogeneous process in the liquid metal-gas phase system. Intensification of such processes is possible by increasing the area of mass exchange which, in this case, is the interfacial surface. For induction furnaces such effect can be obtained by changing the parameters of the electric furnaces i.e. furnace power or its power supply frequency. The article presents impact assessment of the operating power of the furnace upon removal efficiency of lead from $\mathrm{Cu}-\mathrm{Pb}$ alloy melted by VIM technology.

The possibility to reduce the content of a volatile component of the alloy by its evaporation occurs only in case when the pressure of its vapors is clearly higher in comparison with the rest of the ingredients. As the content of a given component in the alloy decreases, its vapor pressure difference decreases compared with the rest of the components. This means that removal of a particular ingredient is only possible to such a boundary content at which vigorous evaporation of other alloy components starts. The value which determines the capability of a given component to evaporate from the alloy is coefficient $\Omega$ defined by the following dependency [7]:

$$
\Omega=\frac{\gamma_{i} \cdot p_{i}^{o}}{\gamma_{j} \cdot p_{j}^{o}}
$$

When condition $\Omega \approx 1$ is fulfilled it is assumed that in the process of smelting the alloy composition does not change. When $\Omega>1$ ' $i$ ' component undergoes larger evaporation (loss) than component ' $j$ '. On the other hand, when $\Omega<1$ the situation is opposite. To assess the value of the evaporation coefficient $\Omega$ from dependence (1), pressure of vapors of particular alloy components above the pure bath i.e. $p_{i}^{o}$ and $p_{j}^{o}$ (in this case copper and lead) and their activity coefficients $\gamma_{i}$ and $\gamma_{j}$ are needed. In order to determined the vapour pressure of the analyzed alloys components over the pure bath, the following dependence was applied:

$$
p_{A}^{o}=\left[\exp \left(-\frac{\Delta_{p} G_{A}^{o}(T)}{R T}\right)\right]
$$

where:

$$
R \text { - gas constant, }
$$

$T$ - temperature, $\Delta_{p} G_{A}{ }^{o}(T)$ - standard free enthalpy of evaporation reaction.

The values of standard free enthalpy for $\mathrm{Cu}-\mathrm{Pb}$ solution were obtained from thermodynamic data base of HSC Chemistry 6 computer program [8]. Figure 1 presents the change of standard value of free enthalpy in analyzed evaporation reactions in the function of temperature.

With the application of estimated values of standard free enthalpy of evaporation reactions of particular alloy components it was possible to calculate their vapours pressure above the pure bath. Fig. 2. shows the change of $p_{C u}^{o}$ and $p_{P b}^{o}$ in function of temperature.

The foregoing, formula (1), means that in order to assess the value of $\Omega$ coefficient it is necessary to know the values of

\footnotetext{
* SILESIAN UNIVERSITY OF TECHNOLOGY, FACULTY OF MATERIALS ENGINEERING AND METALLURGY, 8 KRASINSKIEGO STR., 40-019 KATOWICE, POLAND

** SILESIAN UNIVERSITY OF TECHNOLOGY, FACULTY OF ENERGY AND ENVIRONMENTAL ENGINEERING, 22 KONARSKIEGO STR., 44-100 GLIWICE, POLAND

\# Corresponding author: grzegorz.siwiec@polsl.pl
} 


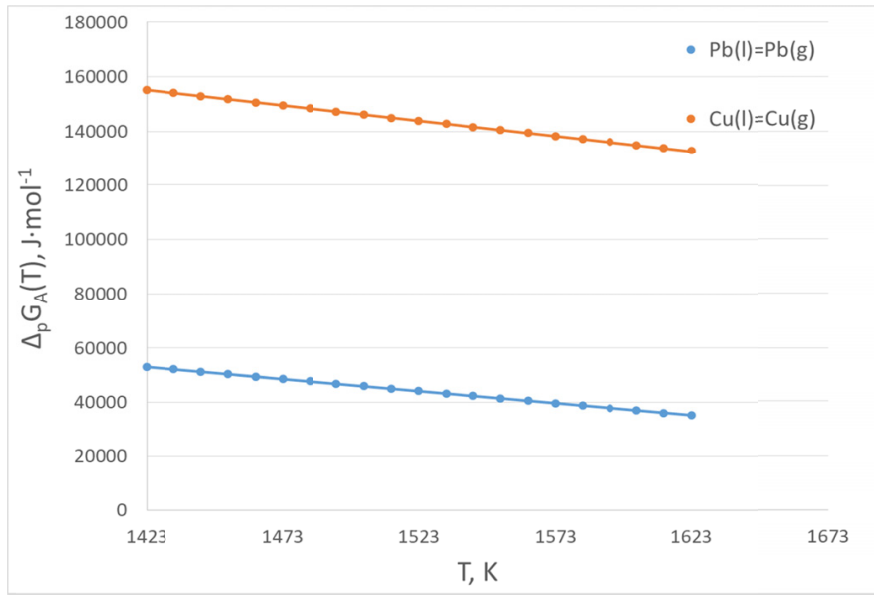

Fig. 1. Change of standard free enthalpy of lead and copper evaporation in temperature function

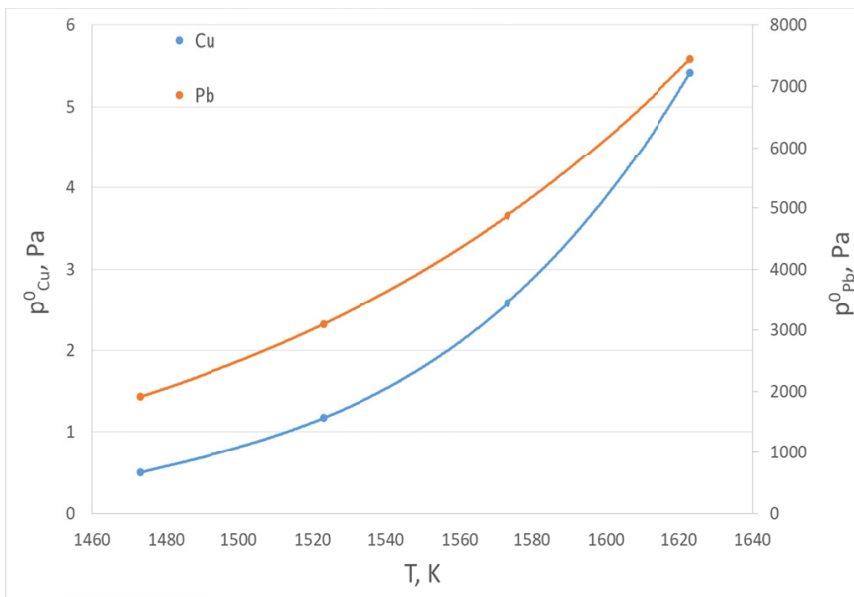

Fig. 2. Change of lead and copper vapour pressure over pure bath in function of temperature

activity coefficients of given components in the analyzed bath. Dependence [9] is used to find the value of $\gamma_{P b}$ coefficients.

$$
\ln \gamma_{P b}=\left(\frac{3360}{T}-0,6\right)\left(1-X_{P b}\right)^{2,1}
$$

Table 1 presents the estimated values of $\gamma_{P b}$ coefficients. For copper it is assumed that its activity is equal to 1.

TABLE 1

Estimated values of activity coefficients of lead in $\mathrm{Cu}-\mathrm{Pb}$ alloys

\begin{tabular}{|c|c|c|}
\hline Pb content, \%mass & Temperature, K & Activity coefficient $\gamma_{P b}$ \\
\hline 2 & \multirow{2}{*}{1473} & 4,73 \\
\hline 1 & & 4,76 \\
\hline 2 & \multirow{2}{*}{1523} & 4,42 \\
\hline 1 & & 4,44 \\
\hline 2 & \multirow{2}{*}{1573} & 4,14 \\
\hline 1 & & 4,17 \\
\hline 2 & \multirow{2}{*}{1623} & 3,90 \\
\hline 1 & & 3,92 \\
\hline
\end{tabular}

High values of evaporation coefficient $\Omega$ (above 1000) obtained from dependence (1) prove that from the thermodynamic point of view evaporation of lead from $\mathrm{Cu}-\mathrm{Pb}$ alloys is possible during their melting in VIM technology.

\section{Research methodology}

Synthetic alloys $\mathrm{Cu}-\mathrm{Pb}$ made of anaerobic copper type M00B and lead type cz.d.a were tested. All experiments were realized in SECO-WARWICK single chamber vacuum induction melting VIM 20-50. It is equipped with state-of art technical solutions used in industrial vacuum devices. They include electrical drive for inductor tilt, panel view used for steering the process and monitoring its parameters, resistance heater for ingot mould, introductory system for alloy additives and sampling mechanism. Furnace basic parameters are listed in Table 2.

TABLE 2

VIM 20-50 basic parameters

\begin{tabular}{|c|c|}
\hline Device parameters & Value of parameter \\
\hline Maximum power & $75 \mathrm{~kW}$ \\
\hline Maximum vacuum & $0.01 \mathrm{~Pa}$ \\
\hline Pump system & $\begin{array}{c}\text { mechanical pump } \\
\text { Roots pump } \\
\text { diffusion pump }\end{array}$ \\
\hline Maximum operating temperature & $2073 \mathrm{~K}$ \\
\hline Maximum capacity of crucible & $20 \mathrm{~kg}$ \\
\hline
\end{tabular}

At the beginning of each experiment an alloy sample with defined mass was placed in a graphite crucible fixed inside the furnace coil. The furnace was locked and the system of pumps started to operate to acquire the assumed pressure in the aggregate. The pressure was maintained by collective operation of mechanical pump, Roots' pump and diffusion pump if needed. Then heating of the charge up to a specified temperature followed. Once the required temperature of metal was reached melting was initiated for 60 minutes and the constant operating power of the furnace was maintained. In strictly defined time intervals metal samples were collected and analyzed for lead content. The analysis were carried out by the method of atomic absorption spectrometry with the use of Perkin Elmer device. Melts with the lead content of $2 \%$ mass were carried out. Furnace operating power was maintained at the level of $20 \%$ to $40 \%$ of its maximum which corresponded to $15 \mathrm{~kW}$ and $30 \mathrm{~kW}$ respectively. The pressure was 10000 and $55000 \mathrm{~Pa}$. As the earlier tests showed [10-12] the evaporation process of lead from $\mathrm{Cu}-\mathrm{Pb}$ performed at this pressure in the induction furnace is not determined by transfer of mass in its liquid phase. This means that the increased stirring of solution by the raised furnace power does not accelerate evaporation 


\section{Results and discussion}

From the kinetic point of view the analyzed evaporation process of lead from liquid copper can be divided into three main stages:

- transfer of lead from deep liquid phase to interfacial surface,

- lead evaporation from liquid metal surface,

- transfer of lead vapours from interfacial surface to gas phase core.

Apart from temperature and pressure responsible for speed of process there are other factors such as chemical composition of metallic bath, gas phase composition and hydrodynamic conditions inside metallurgical aggregate.

Overall mass transfer coefficient is a value which describes the speed of evaporation process. If we assume that the elimination of impurities during vacuum induction smelting can be described by kinetic equation of first order [13] then the overall speed of the process can be described by the following equation:

$$
\frac{d C_{P b}}{d t}=k \cdot \frac{F}{V} \cdot C_{P b}
$$

which in its total form reads:

$$
\int_{o}^{t} \frac{d C_{P b}}{C_{P b}}=-k \cdot \frac{F}{V} \int_{o}^{t} d t
$$

After the integration we get:

$$
2,303 \log \frac{C_{P b}^{t}}{C_{P b}^{o}}=-k \cdot \frac{F}{V}\left(t-t_{o}\right)
$$

where:

$F$ - evaporation surface (interfacial surface)

$V$ - liquid metal volume.

$\left(t-t_{o}\right)-$ process time.

$k$ - overall mass transfer coefficient.

$C_{P b}^{t}-$ lead concentration in alloy after time t,

$C_{P b}^{o}$ - initial lead concentration.

The value of overall mass transfer coefficient $k$ for lead evaporation process is determined from equation (6). However, logarithmic function below correlated the change of lead concentration in liquid copper:

$$
-\log \frac{C_{P b}^{t}}{C_{P b}^{0}}=A+B \cdot t
$$

The value of ' $B$ ' coefficient from equation (7) which describes the change of concentration of this metal in the function of time was used for estimation of transfer coefficient $k$ from equation (6).

Equation (6) shows that correct estimation of the value of overall mass transfer coefficient $k$ for evaporation process requires the knowledge of real mass exchange surface in this case the surface of metallic bath. So far in the majority of cases of kinetic analysis of metal evaporation processes from alloys melted by VIM technology it was assumed that mass exchange surface is approximately equal to the inner surface of the crucible
[14-18]. The risk of significant deformation of the discussed surface due to electromagnetic field operation upon metallic bath has never been taken into consideration.

Numerical analysis was performed to predict the shape and area of molten metal free surface. To fully describe phenomena which occur in the vacuum induction furnace two-way coupling of electromagnetic and fluid dynamic models was developed. Information about the distribution of Loretz force and Joule heat is transferred from EMAG solver to CFD solver and it is introduce as a source term in transport equations. The results of CFD computations including the shape of free surface was applied in the subsequent electromagnetical analysis to create new geometry and mesh. To reduce computing time the geometry was simplified to two dimensional with axisymmetric boundary condition. Despite the applied simplifications defined model showed good agreement with experimental data especially for small input power of inductor which was reported in $[19,20]$.

Set of partially differential equations were solved to predict the electromagnetic field. The magnetic vector potential equation $\mathbf{A}$, magnetic induction $\mathbf{B}$ and eddy current density $\mathbf{J}$ were applied in the following form:

$$
\begin{gathered}
\nabla \times\left(\frac{1}{\mu} \nabla \times \mathbf{A}\right)+j \omega \sigma \mathbf{A}=\mathbf{J}_{\mathbf{s}} \\
\mathbf{B}=\nabla \times \mathbf{A} \\
\mathbf{J}=-j \omega \sigma \mathbf{A}
\end{gathered}
$$

where $\mu$ is the magnetic permeability, $\sigma$ stands for the electric conductivity, $\omega$ denotes the angular frequency and $\mathbf{J}_{\mathbf{s}}$ is the current density source.

The solution of the above differential equation provides information about distribution of Lorentz force $\mathbf{F}_{E M A G}$ and Joule heat $q_{E M A G}$. These quantities were calculated as follows:

$$
\begin{gathered}
\mathbf{F}_{E M A G}=\frac{1}{2} \operatorname{Re}\left(\mathbf{J} \times \mathbf{B}^{*}\right) \\
q_{E M A G}=\frac{|\mathbf{J}|^{2}}{\sigma}
\end{gathered}
$$

Thermo-fluid model was defined in commercial software Ansys Fluent. To obtain the shape of molten metal free surface the set of mass and momentum transport equations was solved. For specified numerical domain these equations were following:

$$
\begin{gathered}
\frac{\partial}{\partial t}\left(\alpha_{q} \rho_{q}\right)+\nabla\left(\alpha_{q} \rho_{q} \mathbf{v}\right)=0 \\
\frac{\partial}{\partial t}(\rho \mathbf{v})+\nabla(\rho \mathbf{v v})=-\nabla p+\mu \nabla^{2} \mathbf{v}+\rho \mathbf{g}+\mathbf{F}_{E M A G}+\mathbf{F}_{s}
\end{gathered}
$$

where $t$ is the time, $\alpha_{q}$ is the volume fraction of the $q^{\text {th }}$ phase, $\rho_{q}$ is the density of the $q^{\text {th }}$ phase, $\mathbf{v}$ is the velocity vector, $p$ is the pressure, $\mu$ is the dynamic viscosity, $\mathbf{g}$ is the gravitational acceleration vector, $\mathbf{F}_{E M A G}$ is the Lorentz Force and $\mathbf{F}_{S}$ is surface tension force. 
Flow within the crucible is strongly turbulent. To simulate this phenomenon simplified RANS $k$ - $\varepsilon$ turbulence model was applied. This model showed satisfying agreement with experiment in previous study. Boundary conditions applied in numerical domain are presented in Fig. 3. Computations were performed for two variants of input power 15 and $30 \mathrm{~kW}$. Numerical results of molten metal free surface are presented in Fig. 4.

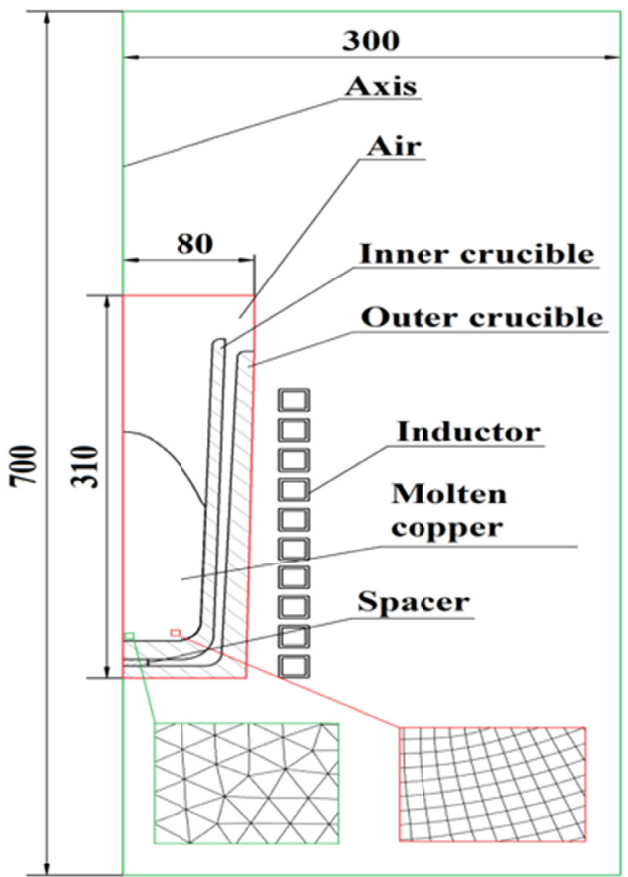

\section{Alumina crucible}

Density: $8000 \mathrm{~kg} \cdot \mathrm{m}^{-3}$

Viscosity: $0.00375 \mathrm{~kg} \cdot \mathrm{m}^{-1} \cdot \mathrm{s}^{-1}$

Electrical resistivity: $1.68 \cdot 10^{-8} \Omega \cdot \mathrm{m}$

Inductor position without spacer included

Fig. 3. Boundary conditions in numerical domain

The initial area of molten metal free surface while the coil was switched off was $0.0088 \mathrm{~m}^{2}$. It was observed that for two variants of input power 15 and $30 \mathrm{~kW}$ this area increased to 0.0111 and $0.0136 \mathrm{~m}^{2}$ respectively.

Collective results of the analyzed evaporation process of lead are listed in Table 3. The values given are mean values

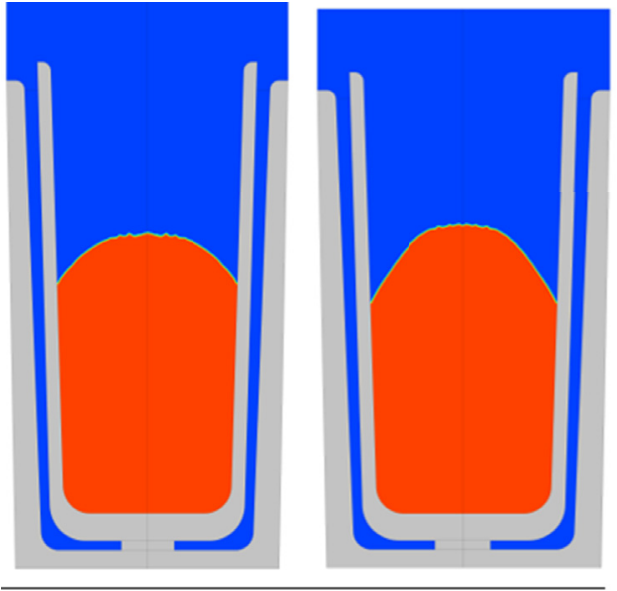

\begin{tabular}{ll} 
Case & Area, $\mathbf{~ m}^{2}$ \\
\hline $20 \%$, & 0.01113 \\
$15 \mathrm{~kW}$ & \\
$40 \%$, & 0.01360 \\
$30 \mathrm{~kW}$ &
\end{tabular}

Fig. 4. Shape and area of molten metal free surface for two variants of input power

obtained for two experiments. The values of overall mass transfer coefficient $k$ are at the level $1-3 \cdot 10^{-5} \mathrm{~m} \cdot \mathrm{s}^{-1}$. They are in very good agreement with the values given by other authors dealing with the evaporation process of lead from liquid copper $[4-6,10]$. The mean stream of evaporating lead was at the level between 20 and $51 \mathrm{~g} \cdot \mathrm{m}^{-2} \cdot \mathrm{min}^{-1}$ and was calculated on the basis of the results of chemical analysis. Its value was growing together with the growth of lead content in an alloy. Numerical simulation performed proved meaningful effect of operating power of the induction furnace upon the shape of the surface of liquid metal being at the same time the surface of evaporation. The observed growth of this surface together with the increase of operating power did not cause the stream of lead leaving the liquid alloy to increase. It is justified since for the range of operating pressures applied in the furnace the velocity of the analyzed process is determined only by phenomena of mass transfer in gas phase.

TABLE 2

Summary results of $\mathrm{Cu}-\mathrm{Pb}$ alloys melt in vacuum induction furnace

\begin{tabular}{|c|c|c|c|c|c|c|}
\hline $\begin{array}{c}\text { Furnace operating } \\
\text { power, } \%\end{array}$ & $\begin{array}{c}\text { Operating } \\
\text { pressure, } \mathrm{Pa}\end{array}$ & $\begin{array}{c}\text { Initial of } \mathrm{Pb} \\
\text { in alloy, \% mass }\end{array}$ & $\begin{array}{l}\text { Content of } \mathrm{Pb} \\
\text { in alloy, } \% \text { mass }\end{array}$ & $\begin{array}{l}\text { Evaporation } \\
\text { surface, } \mathbf{m}^{-2}\end{array}$ & $\begin{array}{c}\text { Overall mass } \\
\text { transfer coefficient } \\
k \cdot 10^{5}, \mathrm{~m} \cdot \mathrm{s}^{-1}\end{array}$ & $\begin{array}{l}\text { Lead stream, } \\
\mathrm{g} \cdot \mathrm{m}^{-2} \cdot \mathrm{min}^{-1}\end{array}$ \\
\hline 20 & 55000 & 1 & 0.699 & 0.0111 & 1.23 & 20.58 \\
\hline 40 & 55000 & 1 & 0.612 & 0.0136 & 1.09 & 22.14 \\
\hline 20 & 55000 & 2 & 1.300 & 0.0136 & 1.29 & 37.54 \\
\hline 40 & 55000 & 2 & 1.201 & 0.0111 & 1.33 & 36.47 \\
\hline 20 & 10000 & 1 & 0.532 & 0.0136 & 2.08 & 50.03 \\
\hline 40 & 10000 & 1 & 0.515 & 0.0111 & 2.11 & 50.90 \\
\hline
\end{tabular}




\section{Summary}

On the basis of the performed investigations and the results of carried out numerical simulations of refining recast from $\mathrm{Cu}-\mathrm{Pb}$ alloys by VIM technology, the following conclusion is reached: together with the growth of operating power of the furnace, interfacial surface liquid metal-gas phase increases significantly as well. Simultaneously the process of lead evaporation from copper becomes more intensive. However, there is no evidence for significant effect of induction furnace operating power upon the value of overall mass transfer coefficient for lead in investigated evaporation process.

\section{Acknowledgements}

The study was conducted under the Research Project No. 2014/13/B/ ST8/02364, financed by the National Science Centre - Poland

\section{REFERENCES}

[1] E. Turkdogan, K. Mills, Trans. Metal. Soc. AIME 230, 750-756 (1964).

[2] R. Ohno, Metall. Trans. B 7, 647-653 (1976).

[3] R. Harris, Metall. Trans. B 15, 251-257 (1984).

[4] M. Yamamoto, E. Kato, Journ. Iron Steel Inst. Japan 66, 608-617 (1980).
[5] L. Blacha, J. Łabaj, Metalurgija 51, 529-533 (2012).

[6] R. Harris, W. G. Dawenport, Metall. Trans. B 13, 581-588 (1982).

[7] J. Guo, G. Liu, Y. Su, H. Ding, J. Jia, H. Fu, Trans. Nonferrous Metals Soc. China 12, 587-591 (2002).

[8] HSC Chemistry Ver.6.1 Copyright (C), Outocumpu Research Oy, Pori, Finland.

[9] J. Wypartowicz, L. Zabdyr, K. Fitzner, Arch. Hutn. 24, 473-479 (1979).

[10] E. Ozberk, R. Guthrie, Inst. Min. Metall. Trans. C 94, 146-157 (1985).

[11] E. Ozberk, R. Guthrie, Metall. Trans. B 17, 87-103 (1986).

[12] L. Blacha, Eliminacja ołowiu i antymonu z miedzi i jej stopów w procesie rafinacji próżniowej. Zeszyty Naukowe Politechniki Śląskiej 60 (2001).

[13] F. D. Richardson, Physical Chemistry of Melts in Metallurgy, Academic Press, London (1974).

[14] R. Ward, Journ. Iron Steel Inst. 201, 920-923 (1963).

[15] R. Ohno, Metall. Trans. B 7B, 647-653 (1976).

[16] E. Harris, Metall. Trans. B 15B, 251-257 (1984).

[17] J. Łabaj, J. Botor, R. Sosnowski, Arch. Metall. 47, 307-320 (2002).

[18] G. Siwiec, Arch. Metall. Mater. 4, 1155-1160 (2013).

[19] P. Bulinski, J. Smolka, S. Golak, R. Przylucki, Przegl. Elektrotechn. 92, 49-52 (2016).

[20] P. Bulinski, J. Smolka, S. Golak, R. Przylucki, M. Palacz, G. Siwiec, J. Lipart, R. Bialecki, L. Blacha, Appl. Thermal Engin. 124, 1003-1013 (2017). 